\title{
Application of thermal analysis and kinetic predictions to YBCO films prepared by Chemical Solution Deposition methods
}

\author{
Silvia Rasi ${ }^{\mathrm{a}, \mathrm{b}}$, Pere Roura-Grabulosa ${ }^{\mathrm{a}}$ and Jordi Farjas ${ }^{\mathrm{a}}$ \\ aUniversitat de Girona, Campus Montilivi, Edif. PII, E17003 Girona, Catalonia, Spain \\ bInstitut de Ciència de Materials de Barcelona, ICMAB - CSIC, Campus UA Barcelona, E-08193 \\ Bellaterra, Catalonia, Spain
}

*Corresponding author: Jordi Farjas

Keywords: Kinetic analysis; TFA-YBCO; Thermal analysis; Films; CSD, kinetic predictions.

\begin{abstract}
Fluorine-based chemical solution deposition routes to prepare $\mathrm{YBa}_{2} \mathrm{Cu}_{3} \mathrm{O}_{7-\partial}$ films were characterized with the aid of thermal analysis techniques. Thermogravimetric analysis and X-ray diffraction were applied to characterize the main steps of the fluorine-based route: pyrolysis of the organic material and growth of the oxide. The difference between the thermal behaviour of films and powders in fluorine-based chemical solution deposition route is reiterated to justify the importance of the study of films. Finally, the kinetic analysis is used to predict the mass evolution of the pyrolysis for an arbitrary temperature program with the aim to optimize this treatment to minimize film porosity and crack formation.
\end{abstract}

\section{Introduction}

Thermal analysis (TA) comprises a number of techniques that study the evolution of a property of a system as a function of temperature, in a controlled atmosphere. For instrumental reasons concerning the sensitivity and signal-to-noise ratio of such properties, normally TA is applied to samples in the form of powder, even when the main interest is the understanding of the thermal behaviour of the corresponding film. However, extrapolating the thermal behaviour of films from that of the corresponding powder is likely to lead to erroneous conclusions regarding decomposition temperatures, decomposition mechanism and kinetics [1-5].

In many gas-solid reactions, such as thermal decompositions, controlled by the transport of gaseous species to or out of the sample, films behave differently than powders [6-9]. This is a consequence of their geometry: films have a higher surface/volume ratio which results in a faster renewal of the local atmosphere. Conversely, in powders, gas transport through interstices is slow, resulting in a locally inert atmosphere in the bulk. For similar reasons, the heat transport is also different $[10,11]$ : in films, heat dissipation is much easier than in powders, making combustion virtually impossible [6].

Understanding the actual phenomena that occur during the decomposition of films is crucial for chemical solution deposition (CSD) methods $[12,13]$. CSD methods have arisen as a promising and cost-effective alternative to manufacture ceramic films. In particular, large-scale applications such as coated conductors based on high-temperature superconducting $\mathrm{YBa}_{2} \mathrm{Cu}_{3} \mathrm{O}_{7-\partial}$ (YBCO) layers 
[14-16], are still limited by their production costs, as a consequence of the fact that their synthesis is based on ultra-high vacuum processes $[17,18]$. Conversely, CSD methods rely on the use of commercial precursors processed through a few simple steps: solution deposition, pyrolysis (in our study, thermal decomposition of the precursor film in wet oxygen or nitrogen) and growth of the oxide. The solution is generally composed of metalorganic precursors that, after deposition, generate an amorphous film which later undergoes two thermal treatments. During pyrolysis, carried out typically between 100 and $350^{\circ} \mathrm{C}$, the organic part is removed and the film undergoes shrinkage and volume reduction. Finally, during growth, at higher temperatures, the inorganic material crystallizes.

The preparation of YBCO through CSD methods relies on two main approaches, distinguished according to their respective fluorine content: fluorine-free methods (FF) [19] and fluorine-based routes, such as the trifluoroacetate (TFA) route [20]. Contrarily to FF routes, the TFA route is a welldeveloped and understood approach [21-25], where the main species after pyrolysis consist of oxides, fluorides and oxyfluorides. Here, YBCO crystallizes upon fluorine removal as hydrofluoric acid (HF) during the growth step [5,22,24,25]; but fluorine removal is slow because it is significantly affected by the low HF equilibrium vapour pressure in the furnace. Additionally, HF is not environmentally-friendly. As a consequence, the TFA route requires complex furnace designs. For all these reasons, low-fluorine routes (LF) [26-28] have developed, where the amount of fluorine in the metalorganic precursors is reduced.

To obtain high performance films with the final desired properties, each of these steps needs to be studied and adjusted. To this aim, TA can be applied in-situ. The evolution of the transformation monitored with TA techniques such as thermogravimetry (TGA) can then be described through kinetic models. Kinetic methods are applied to derive kinetic parameters of the models, such as the apparent activation energy and the pre-exponential factor of the kinetic constant. These parameters can later be used to predict the evolution under a different temperature program. Among the kinetic methods, isoconversional ones [29-32] are extensively used because they allow for the determination of the kinetic parameters without assuming any particular reaction model.

This work will show the usefulness of in situ TA to analyse the behaviour of metalorganic precursor films undergoing a temperature programme in a controlled atmosphere. In particular, we will analyse one TFA and one LF YBCO precursor solution. The TFA precursor film will be analysed by TGA and X-ray diffraction (XRD) of the solid residues. We will show that gas transport plays a crucial role in the context of the TFA-CSD methodology used to manufacture YBCO films. Concerning the LF precursor, a kinetic analysis will be carried out to predict the mass loss behaviour of films upon heating.

\section{Material and methods}

The salts used for the solution preparation were the following: $\mathrm{Y}\left(\mathrm{CF}_{3} \mathrm{CO}_{2}\right)_{3}$ (YTFA, SigmaAldrich, $\geq 99 \%$ ), $\mathrm{BaCO}_{3}$ (Diopma, $\left.\geq 99 \%\right), \mathrm{Ba}\left(\mathrm{CH}_{3} \mathrm{COO}\right)_{2}\left(\mathrm{BaAc}_{2}\right.$, Sigma-Aldrich $\left.\geq 99.5 \%\right), \mathrm{Cu}\left(\mathrm{CH}_{3} \mathrm{CO}_{2}\right)_{2}$ ( $\mathrm{CuAc}_{2}$, Alfa-Aesar $\geq 98 \%$ ), $\mathrm{CuCl}_{2}$ (RP Carlo Erba, $\geq 99 \%$ ). Propionic acid (Sigma-Aldrich $\geq 99.5 \%$ ) and methanol ( $\mathrm{MeOH}$, Sigma-Aldrich $\geq 99.5 \%$ ) were used as solvents and triethanolamine (TEA, Sigma- 
Aldrich $\geq 98 \%$ ) as chelating agent.

Trifluoroacetic acid (TFAH, Sigma-Aldrich $\geq 99 \%$ ) was used to prepare $\mathrm{Ba}\left(\mathrm{CF}_{3} \mathrm{CO}_{2}\right)_{2}(\mathrm{BaTFA})$ and $\mathrm{Cu}\left(\mathrm{CF}_{3} \mathrm{CO}_{2}\right)_{2}$ (CUTFA). BaTFA was obtained from milled $\mathrm{BaCO}_{3}$ dissolved in a solution of deionized water and TFAH (water/TFAH ratio of 1/1.5). CuTFA was obtained from a solution of $\mathrm{CuCl}_{2}$ in deionized water, upon addition of $\mathrm{NaOH}$. The precipitate, $\mathrm{Cu}(\mathrm{OH})_{2}$, was washed with deionized water and, afterwards, was mixed with TFAH in excess. Finally, the precipitates of BaTFA and CuTFA were filtered and washed in $\mathrm{MeOH}$.

The two solutions used in this study were prepared with low-fluorine (LF) and trifuoroacetate (TFA) salts. LF solutions were obtained dissolving YTFA, $\mathrm{BaAc}_{2}$ and $\mathrm{CuAc}_{2}$ in a mixture of $\mathrm{MeOH}$ with a $20 \%$ volume of propionic acid and $5 \%$ volume of TEA. TFA solutions were prepared dissolving CUTFA, BaTFA and YTFA in MeOH. In both solutions the total metal concentration was $1.5 \mathrm{M}$ (with $\left[\mathrm{Y}^{3+}\right]=0.25 \mathrm{M},\left[\mathrm{Ba}^{2+}\right]=0.5 \mathrm{M}$ and $\left.\left[\mathrm{Cu}^{2+}\right]=0.75 \mathrm{M}\right)$.

ICP analysis was performed in a Thermo Elemental model PQEXcell. Metal stoichiometry of solutions determined by ICP analysis was (Y:Ba:Cu) $1: 2 \pm 0.05: 3 \pm 0.05$. Also water content in the solutions was measured by the Karl-Fischer method [33] and was found to be below 1\%wt for TFA solutions and below $2 \%$ wt for LF solutions.

Films were obtained by drop casting the solutions on $\mathrm{LaAlO}_{3}(\mathrm{LAO})$ substrates of size $10 \times 10$ $\mathrm{mm}$. The final film thickness was calculated with the following formula:

$$
H=m /(d \cdot S) \text {, }
$$

where $m$ is the final mass of the film, $d$ is the particle density of the oxide/oxifluorides species after pyrolysis and $S$ is the area of the substrate.

TGA experiments were carried out in a Mettler Toledo thermo-balance, model TGA/DSC1. High purity $\mathrm{N}_{2}$ and $\mathrm{O}_{2}$ (impurity level below $5 \mathrm{ppm}$ ) at a flow rate $50 \mathrm{ml} \mathrm{min}^{-1}$ were used to control the furnace atmosphere. Water-saturated gases were obtained by bubbling the carrier gas in water at $25^{\circ} \mathrm{C}$ and atmospheric pressure. A flow of $10 \mathrm{ml} \mathrm{min}^{-1}$ of dry $\mathrm{N}_{2}$ was used to protect the balance. XRD analysis was performed in a PANalytical diffractometer model X'Pert PRO MRD using a 4-angle goniometer and primary optics consisting of a parabolic mirror and a 4-crystals Ge-(220) Bartels monochromator. The measurement geometry was optimized to increase the sample signal with respect to the substrate peaks. The X-ray beam wavelength was $1.5418 \AA$ ( $\mathrm{Cu}$-K $\alpha$ ).

\section{Results and discussion}

\subsection{The TFA-YBCO route}

Phase evolution during the heating ramp at constant rate

First, we will show that it is possible to monitor in-situ the processes that take place during film pyrolysis and growth of YBCO. The TG analysis of a TFA film decomposed in humid $\mathrm{N}_{2}$ is reported in Fig. 1a. Both the pyrolysis of the organic material, at temperatures below $350^{\circ} \mathrm{C}$, and $\mathrm{YBCO}$ growth between 550 and $850^{\circ} \mathrm{C}$ are shown. After pyrolysis, the species consist of CuO and BYF (a fluoride with formula $\mathrm{Ba}_{1-x} \mathrm{Y}_{x} \mathrm{~F}_{2+x}$ ), as shown in Fig. $1 \mathrm{~b}$ (the particular value of $2 \theta$ of the BYF may shift depending on its stoichiometry). Note, from Fig. 1.a that the mass recorded by the TG at $350^{\circ} \mathrm{C}$ corresponds to the expected mass for the formation of $\mathrm{CuO}$ and BYF. Based on the stoichiometry 
reported from selective electrode [24] and XRD measurements [22,34], we have taken $x=0.33$ to calculate this mass loss.

The TG analysis reveals that between 310 and $550^{\circ} \mathrm{C}$ the mass is nearly constant; thus, no significant transformation is taking place. This result is in agreement with the XRD analysis which does not show significant differences between films quenched at 310 and $500^{\circ} \mathrm{C}$. At $550^{\circ} \mathrm{C}$ the mass starts to decrease; at $600^{\circ} \mathrm{C}$ the mass has approached the expected mass for the formation of yttrium oxyfluoride (YOF), barium oxyfluoride $\left(\mathrm{Ba}(\mathrm{O}, \mathrm{F})_{2}\right.$ abbreviated as $\left.\mathrm{BOF}\right)$ and $\mathrm{CuO}$. Indeed, the $\mathrm{XRD}$ analysis of a sample quenched at $600^{\circ} \mathrm{C}$ shows the presence of these phases. Thus, the first step after pyrolysis is the decomposition of BYF to yield YOF and BOF. Afterwards the mass further decreases, approaching the expected mass to form yttrium oxide; in fact, a quenched film at $810^{\circ} \mathrm{C}$ clearly shows the presence of $\mathrm{Y}_{2} \mathrm{O}_{3}$.

(a)

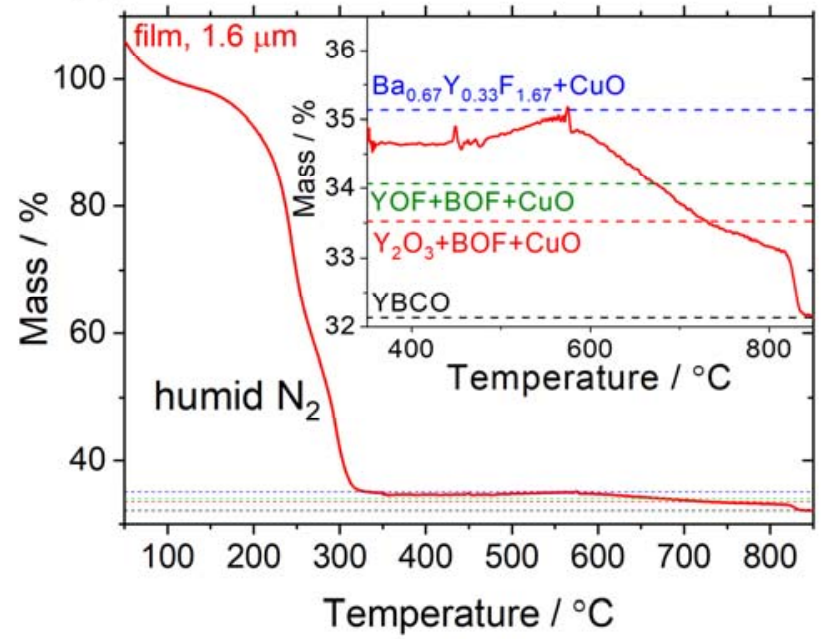

(b)

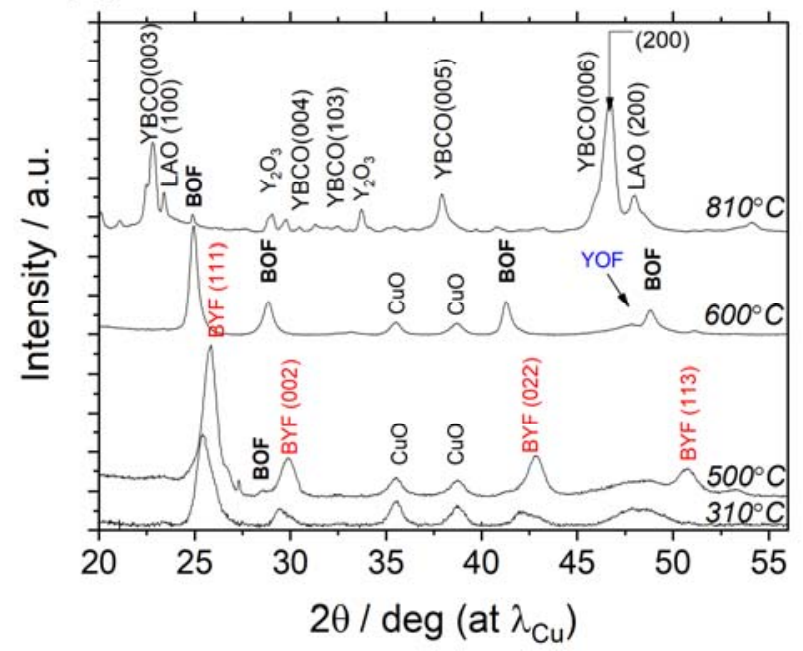

Fig.1: (a) TG analysis of a film obtained from deposition of the TFA solution. Conditions: flowing humid $\mathrm{N}_{2}$, heated at $5^{\circ} \mathrm{C} \mathrm{min}^{-1}$ up to $350^{\circ} \mathrm{C}$, and at $25^{\circ} \mathrm{C} \mathrm{min}^{-1}$ from $350^{\circ} \mathrm{C}$ to $850^{\circ} \mathrm{C}$. Dashed horizontal lines indicate the theoretical final mass to yield the intermediates before $Y B C O$ formation. Inset: enlargement of the TG curve in the temperature range from $350^{\circ} \mathrm{C}$ to $850^{\circ} \mathrm{C}$. (b) XRD of the solid residue after decomposition of the TFAfilms during pyrolysis and growth at $5{ }^{\circ} \mathrm{C} \mathrm{min}^{-1}$ up to a given temperature (indicated) under a humid $\mathrm{N}_{2}$ flow.

The final stage is the formation of $\mathrm{YBCO}$ from $\mathrm{Y}_{2} \mathrm{O}_{3}, \mathrm{BOF}$ and $\mathrm{CuO}$ upon reaction with water vapour. Two main competitive YBCO growth paths can occur from these phases [22,35], and they are represented by Eqs. 2 and 3 (not balanced, for purposes of simplicity):

$$
\begin{gathered}
\mathrm{BOF}_{(s)}+\mathrm{CuO}_{(s)}+\mathrm{Y}_{2} \mathrm{O}_{3(s)}+\mathrm{H}_{2} \mathrm{O}_{(g)} \rightarrow \mathrm{YBCO}_{(s)}+\mathrm{HF}_{(g)} \\
\mathrm{BOF}_{(s)}+\mathrm{CuO}_{(s)}+\mathrm{Y}_{2} \mathrm{O}_{3}(s)+\mathrm{Y}_{22} 25_{(s)}+\mathrm{H}_{2} \mathrm{O}_{(g)} \rightarrow \mathrm{YBCO}_{(s)}+\mathrm{HF}_{(g)}
\end{gathered}
$$

where $\mathrm{Y} 225$ is the $\mathrm{Y}_{2} \mathrm{Cu}_{2} \mathrm{O}_{5}$ phase.

At $810^{\circ} \mathrm{C}$, YBCO formation is not complete yet, but most of the BOF precursor has disappeared (Fig. 1b) while YBCO has crystallized. Crystallization of YBCO occurs through the reaction of water vapour with the fluorinated intermediate phases to yield the oxides and gaseous $\mathrm{HF}$. The TG signal shows that the mass loss in the range from $600^{\circ} \mathrm{C}$ to $830^{\circ} \mathrm{C}$ is slow and smooth. Indeed, the mechanism that limits the kinetics of this final stage is $\mathrm{HF}$ diffusion, and it is responsible for the small growth rates $\left(\sim 1 \mathrm{~nm} \mathrm{~s}^{-1}\right)$ of this CSD route $[5,21,25,36]$. 
Finally, under the same conditions, crystallization of YBCO occurs easily in films (at $810^{\circ} \mathrm{C}$ in Fig.1b) while it is much more difficult in powders [37]. Indeed, this is due the fact that the renewal of the local atmosphere is easier in films than in powders due to the higher surface/volume ratio of the film. Conversely, in powders, $\mathrm{H}_{2} \mathrm{O}$ transport and $\mathrm{HF}$ out-diffusion through interstices are hindered. Therefore, the analysis of the thermal behaviour of powders is inadequate to understand the evolution of the different transformations that take place during the growth of YBCO films.

\section{Film thickness and pyrolysis}

One major goal to make CSD a competitive technology in the manufacturing of YBCO tapes is to grow thick films of at least $1 \mu \mathrm{m}$. Most solid-gas reactions that take place during pyrolysis are controlled by gas diffusion. Therefore, one should expect a shift to higher decomposition temperatures for thick films. Consequently, it cannot be assumed that the temperature program used to grow thin films is appropriate to grow thicker films. Since TA permits the monitoring of the evolution during pyrolysis, it can be used to optimize the temperature program of this stage.

In Fig. 2 we report the mass evolution of three films of different thickness during the pyrolysis temperature profile that has been used for the growth of $0.3 \mu \mathrm{m}$ films. It consists of a heating ramp at $5^{\circ} \mathrm{C} \mathrm{min}-1$ up to $310^{\circ} \mathrm{C}$ followed by an isotherm of 30 minutes at this temperature. From Fig. 2 it is clear that as thickness increases there is a shift of the mass-loss step to higher temperatures during the heating ramp. One can also verify that the decomposition is nearly completed at the end of the heating ramp only for the thinnest film. So, in this case, the isotherm can be shortened. On the contrary, for the thickest film, the decomposition is far from completion at the end of the ramp. Thus, in this case, the isotherm must be longer.

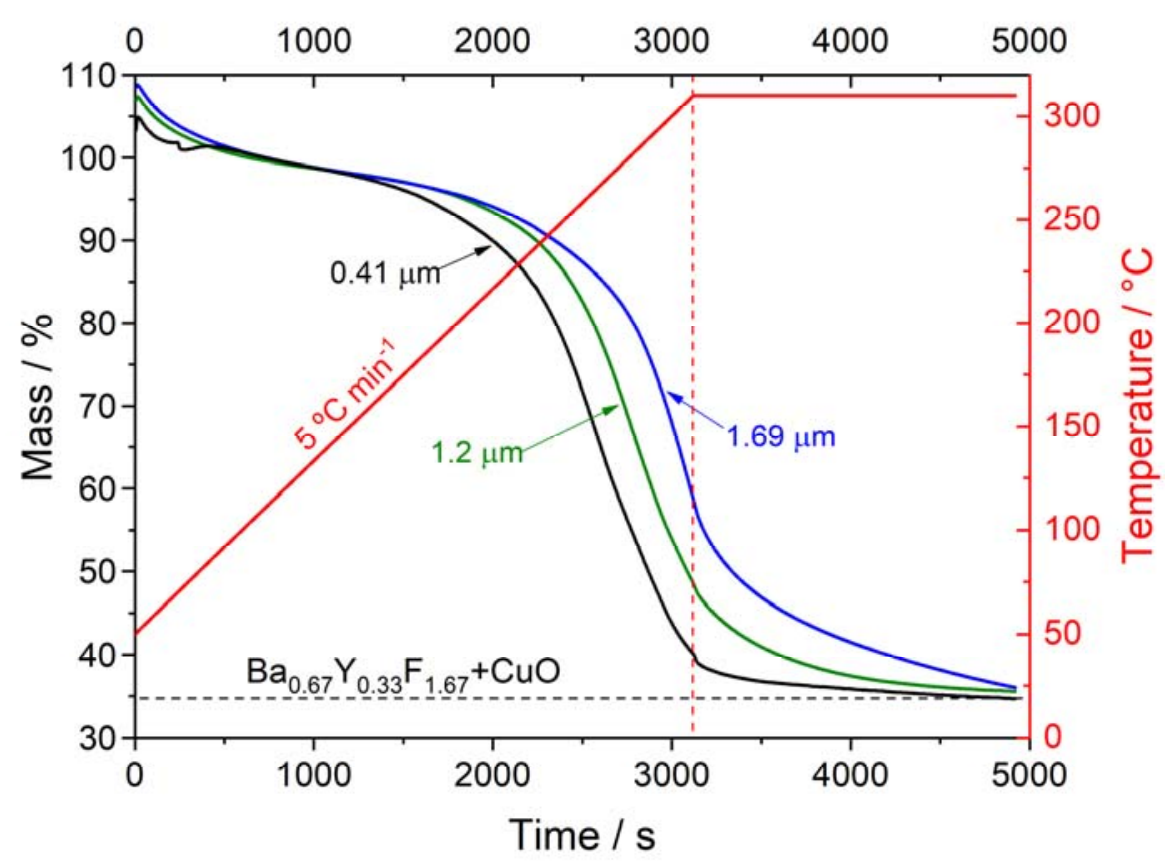

Fig. 2: TG curves of TFA precursor when heated at $5^{\circ} \mathrm{C} \mathrm{min}-1$ up to $310^{\circ} \mathrm{C}$ and afterwards kept at this temperature for 30 minutes under a flow of humid $N_{2}$. Increasing the thickness, the decomposition temperature increases. The mass is normalized to the sample mass after solvent evaporation. 


\subsection{The LF route: kinetic analysis of the pyrolysis step}

During film pyrolysis, the organic fraction of the precursors is removed. As a result, there is a huge shrinkage of the film and a significant amount of volatiles evolves. Therefore, it is critical to avoid fast shrinkage and fast gas release to prevent crack formation, wrinkling and film porosity, because the latter are detrimental to the performance of the final YBCO film. For this reason, pyrolysis should be performed at a controlled low decomposition rate. Besides, thermal treatment optimization is crucial to achieve film homogeneity after pyrolysis [38-40]. For this purpose, thermal analysis is useful because it monitors the evolution of the mass of a film during a particular temperature program. In addition, the use of kinetic methods permits us to make predictions about the evolution of the degree of decomposition, and they thus significantly simplify the task of optimizing the thermal treatment.

\section{Determination of kinetic parameters using the Friedman method}

The first step is to perform a kinetic analysis to determine the kinetic parameters, i.e., to fit the data with a kinetic model. In particular, isoconversional methods are based on the hypothesis that at a given degree of transformation, $\alpha$, the transformation rate is only a function of the temperature:

$$
\left[\frac{d \ln (d \alpha / d t)}{d T^{-1}}\right]_{\alpha}=-\frac{E_{\alpha}}{R},
$$

where $T$ is the temperature, $E_{\alpha}$ is the apparent activation energy at a particular value of $\alpha$ and $R$ is the gas constant. From integration of Eq. (4) we obtain:

$$
\frac{d \alpha}{d t}=A_{\alpha} \exp \left[-\frac{E_{\alpha}}{R T}\right] f(\alpha),
$$

The evolution of the decomposition can be calculated from Eq. 5 provided that we know the kinetic parameters, $E_{\alpha}$ and $A_{\alpha} f(\alpha)$ (note that these are a function of $\alpha$ ). The goal of isoconversional methods is to determine these kinetic parameters. To do so, it is necessary to perform a set of measurements under different temperature programs (isothermal or non-isothermal).

We chose non-isothermal measurements because they are easier and faster to perform and can examine a wider temperature range [41]. Since, as shown in Fig.2, the kinetics of pyrolysis usually depends on the film thickness, it is compulsory to analyse films of similar thickness. In Fig. 3 we plotted the TG curves obtained from films with a thickness of about $1 \mu \mathrm{m}$ under the effect of four different heating rates: $\beta_{i}=5,10,20$ and $40{ }^{\circ} \mathrm{C} \mathrm{min}-1$. These set of measurements will be used to determine the kinetic parameters discussed above. 


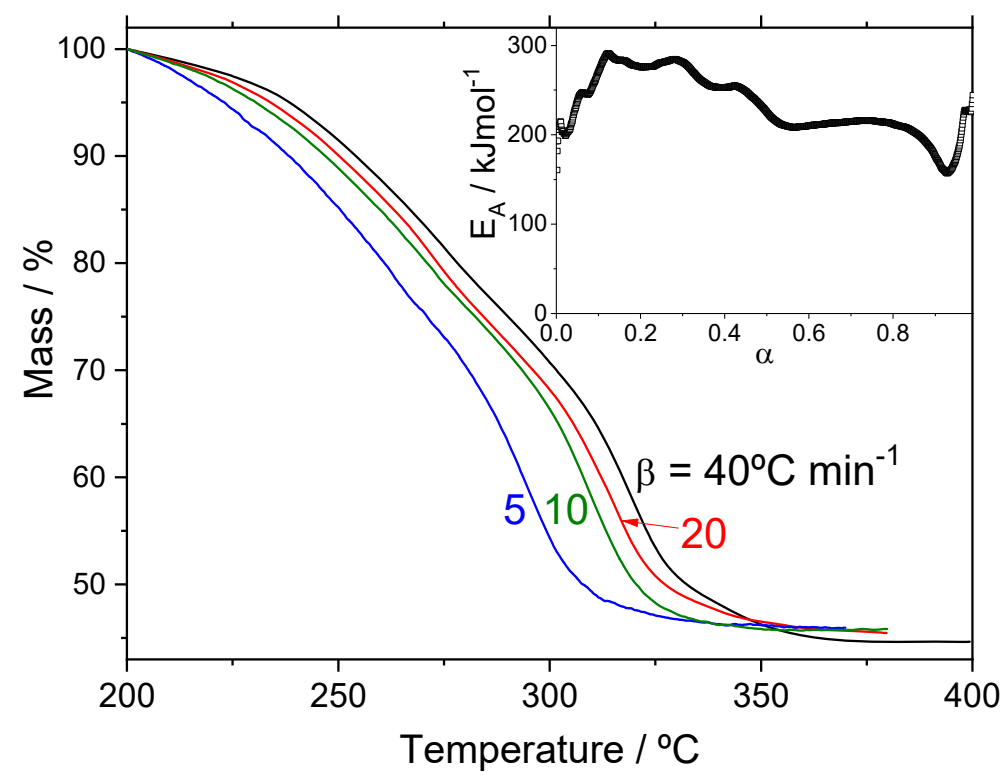

Fig. 3. Evolution of the mass (normalized to the mass after solvent evaporation at $200^{\circ} \mathrm{C}$ ) when the $L F$ precursor is heated at several constant rates. Experiments were performed under a flow of humid oxygen. Inset: activation energy determined with the Friedman isoconversional method, Fig.

5.

If we assume that the degree of transformation is proportional to the sample mass loss, the curves $\alpha(T)$ and $\alpha(t)$ can be easily calculated assuming that initially the degree of transformation is zero ( $\alpha=0$ when $m=100 \%)$, and that the transformation is complete $(\alpha=1)$ when the mass is constant. Fig. 4 shows the $\alpha(t)$ curves extracted from Fig. 3.

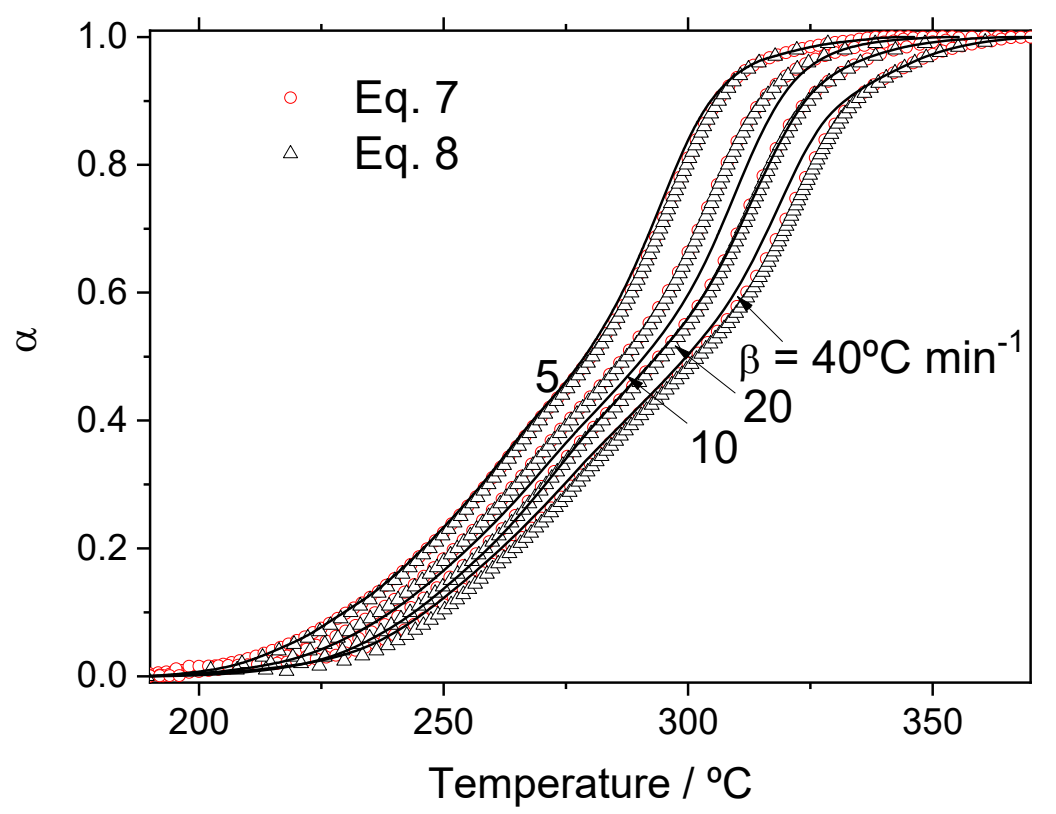

Fig. 4. Degree of transformation as a function of temperature for four LF films with similar thickness. The solid line is the evolution of the transformed fraction extracted from Fig. 3. The symbols are the non-isothermal predictions given by Eq. 7 (circles) and Eq. 8 (triangles). 
Because of its simplicity and accuracy, we chose the isoconversional Friedman method [42] to obtain the kinetic parameters. From the natural logarithm of Eq. 5 we obtain:

$$
\ln \left[\frac{d \alpha}{d t}\right]=-\frac{E_{\alpha}}{R T}+\ln \left[A_{\alpha} f(\alpha)\right]
$$

Thus, to determine $E_{\alpha}$ and $A_{\alpha} f(\alpha)$ for a given value of $\alpha$, it is necessary to calculate, for each heating rate, $\beta_{i}$, the corresponding transformation rate, $d \alpha /\left.d t\right|_{\beta_{i}}$, and temperature, $T_{\alpha, i}$. Then, according to Eq. 6, $E_{\alpha}$ and $A_{\alpha} f(\alpha)$ are the slope and the y-intercept, respectively, of the plot of $\ln \left[d \alpha /\left.d t\right|_{\beta_{i}}\right]$ versus $1 / T$. The Friedman analysis for $\alpha=0.1$ to 0.9 is reported in Fig 5.

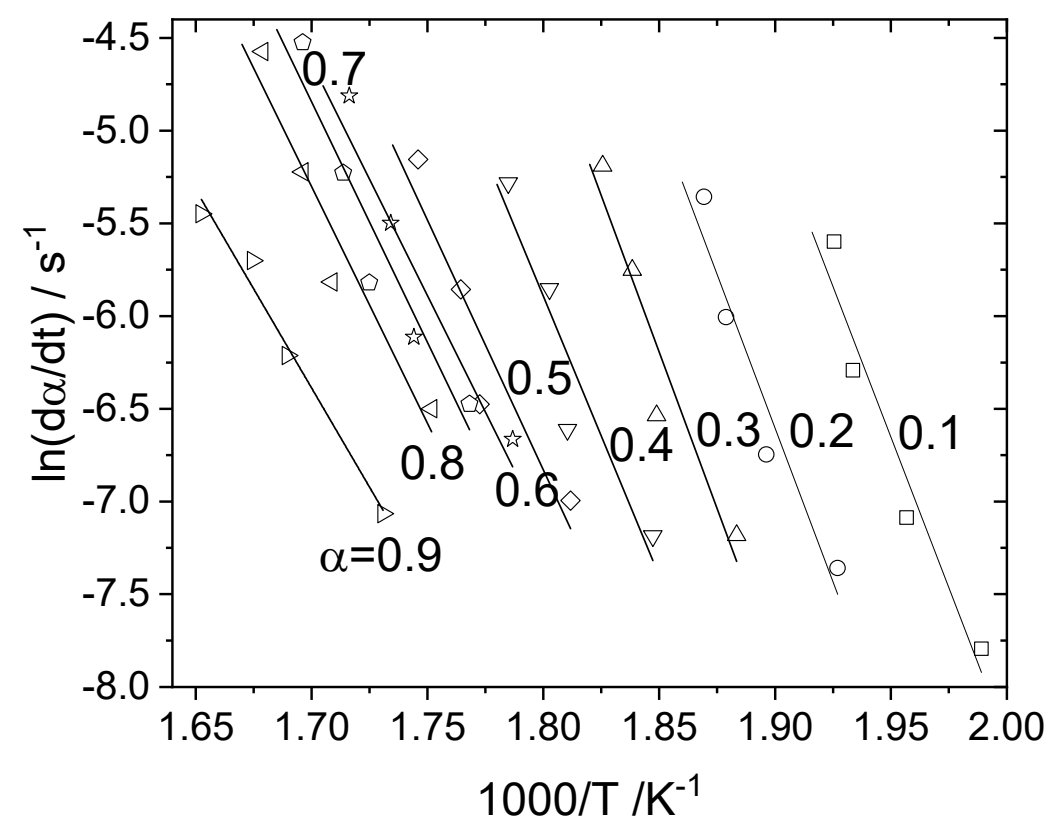

Fig 5. Friedman plot for selected values of the transformed fraction, $\alpha$. Four points are plotted for each $\alpha$ which correspond to $\beta=5,10,20$ and $40^{\circ} \mathrm{C} \mathrm{min}^{-1}$.

The Friedman method is a derivative method because it is based on the calculation of the time derivative of the $\alpha(t)$ curves. Since the time derivative is very sensitive to experimental noise and in films we are dealing with small sample masses, it is recommended to smooth the data before calculating the time derivative [30]. We have used a first order polynomial Savitzky-Golay filter [43], taking care that the smoothed curve is not distorted with respect the raw data. To determine the transformation rate and temperature at a given $\alpha$ value (and obtain the plot shown in Fig. 5), it is necessary to discretize $\alpha$, so that $\alpha_{j}=j / N$ where $N$ is the number of discrete values of $\alpha_{j}$ ( $0 \leq j \leq$ $N)$. Afterwards, using an interpolation algorithm [43], one can determine for each $\alpha_{j}$ the parameters $d \alpha /\left.d t\right|_{j}$ and $T_{j}$. To perform a reliable prediction, $N$ should be relatively large; we chose $N=1000$. The $N$ values of $E_{j}$ determined from the Friedman analysis are shown in the inset of Fig. 3 . Note that $E_{\alpha}$ is not constant; this is a characteristic feature of complex processes. Indeed, the shape of the TG curves already revealed that the precursor decomposition is not a simple process.

\section{Kinetic predictions}

Once we have determined $E_{j}$ and $\left.A_{\alpha} f(\alpha)\right|_{j}$, the kinetic evolution can be calculated from Eq. 5. There are several methods, but two particular methods were chosen because they permit the 
calculation of the evolution for an arbitrary temperature program, $T(t)[44,45]$. To apply these methods, it is necessary to discretize the temperature program at time intervals, $\Delta t$. Under this discretization, the temperature $T_{k}$ is the temperature at the time instant $t_{k}=k \cdot \Delta t$.

The first method is based on the summation of Eq. 5 over $\Delta t$ intervals:

$$
\alpha_{k+1}=\alpha_{k}+\left.A_{\alpha} f(\alpha)\right|_{k} \cdot \exp \left(-\frac{E_{k}}{R T_{k}}\right) \Delta t
$$

Clearly, $\Delta t$ should be small enough to consider $T$ approximately constant during the time interval $\Delta t$. For a given $\alpha_{k}$, the related values of $E_{k}$ and $\left.A_{\alpha} f(\alpha)\right|_{k}$ can be obtained from interpolation of the $E_{k}$ and $A_{\alpha} f(\alpha)$ values at $\alpha_{k}$. Then, the calculation of $\alpha_{k+1}$ is straightforward from the iterative application of Eq. 7 starting from $\alpha_{0}=0$.

The second method makes use of $\alpha$ discretization previously used to determine the kinetic parameters. In particular, it is based on the calculation of the time $t_{j}$ necessary to achieve a degree of transformation $\alpha_{j}=j / N$ [44]:

$$
\begin{aligned}
t_{j}=t_{k_{j}}+\left\{\frac{1}{n_{\exp }} \sum_{i=1}^{n_{\exp }} \frac{E_{j}}{R \beta_{i}}\left[p\left(\frac{E_{j}}{R T_{j, i}}\right)-p\left(\frac{E_{j}}{R T_{j-1, i}}\right)\right]\right. \\
-\left[\exp \left(-\frac{E_{j}}{R T_{k_{j-1}}}\right)\left(t_{k_{j-1}+1}-t_{j-1}\right)\right. \\
\left.\left.+\sum_{k=k_{j-1}+2}^{k_{j}} \exp \left(-\frac{E_{j}}{R T_{k}}\right) \Delta t\right]\right\} \exp \left(-\frac{E_{j}}{R T_{k_{j}}}\right)
\end{aligned}
$$

where $t_{k_{j}}$ is the largest time of the temperature program discretization that is smaller than $t_{j}\left(t_{k_{j}}<\right.$ $\left.t_{j}<t_{k_{j}+1}\right), T_{j, i}$ is the temperature when a degree of transformation $\alpha_{j}$ is reached at a constant heating rate $\beta_{i}, p(x)$ is the so called temperature integral and $n_{\text {exp }}$ is the number of experiments performed at different heating rates $\left(\beta_{i}, 0 \leq i<n_{\text {exp }}\right)$. $t_{j}$ is determined applying Eq. 8 iteratively starting from $t_{0}=0$ at $\alpha_{0}=0$. Details about the derivation of Eq. 8 as well as a guide for its application are given in the appendix (in ref. [41], Eq. 8 was erroneously typed and given without derivation).

Results

After obtaining the kinetic parameters from the Friedman plot, they can now be applied to make predictions. First, we did a self-consistency test consisting of calculating the evolution of $\alpha$ for the four experiments used in the isoconversional analysis, and the result is plotted as symbols in Fig. 4. We can state that there is a fair amount of agreement between the predictions and the measured evolution.

Secondly, we calculated the predicted evolution for two different thermal treatments: (i) heating at $5^{\circ} \mathrm{C} \mathrm{min}^{-1}$ up to $290^{\circ} \mathrm{C}$ followed by a 40 -minute isotherm at $290^{\circ} \mathrm{C}$, and (ii) heating at $3^{\circ}$ $\mathrm{C} \mathrm{min}^{-1}$ up to $260^{\circ} \mathrm{C}$ followed by a heating ramp of $2^{\circ} \mathrm{C} \mathrm{min}^{-1}$ up to $370^{\circ} \mathrm{C}$. To check these predictions, 
we measured the experimental evolution of two films using these temperature programs. Figs. 6 and 7 report the predicted evolutions using the two methods previously described, together with the experimental data; one can verify that the predictions are again in fair agreement with the observed evolution. Furthermore, it can be verified that the second temperature program permits the achievement of a more progressive decomposition, and thus it may be better suited for the prevention of crack formation and porosity.

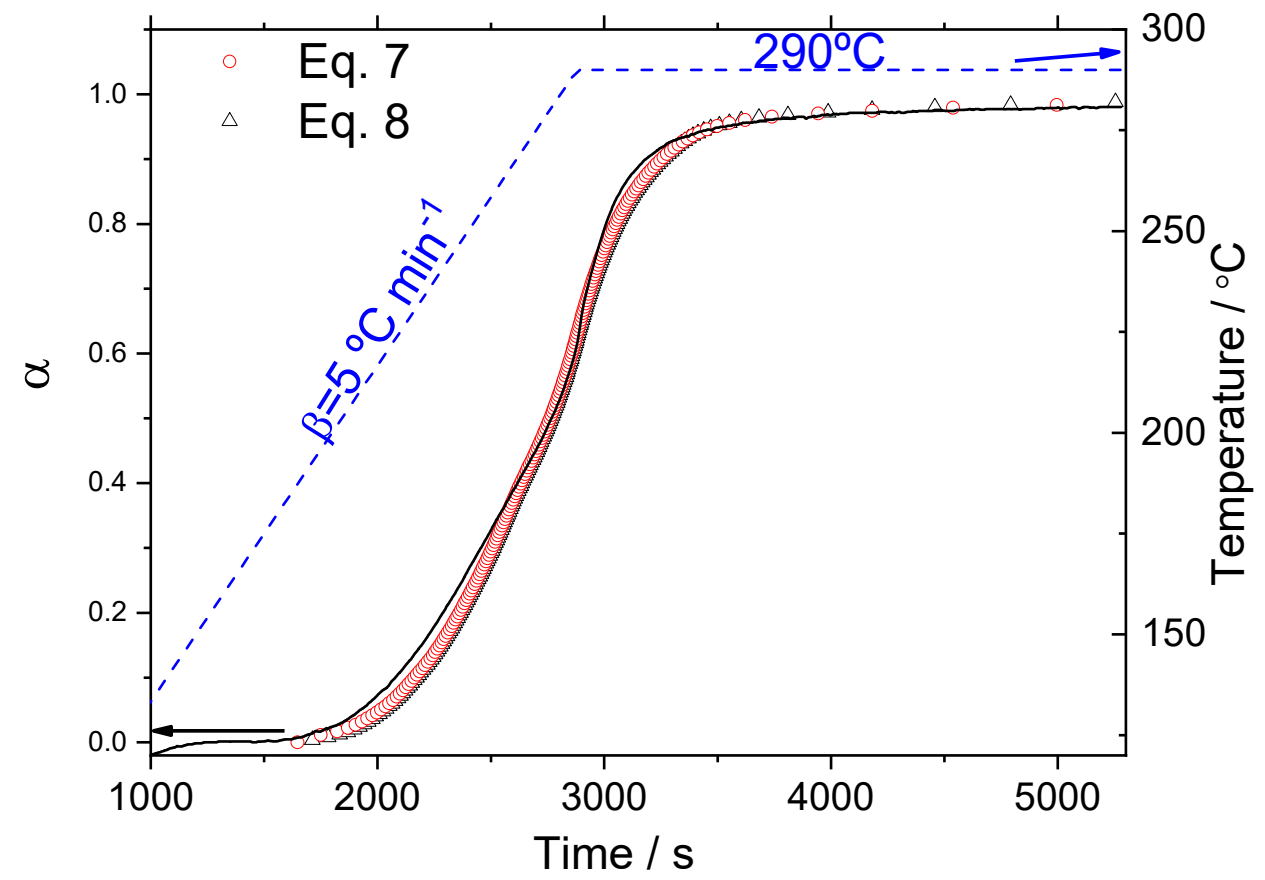

Fig. 6. Solid line: evolution of the transformed fraction when the LF precursor film undergoes a treatment with a heating ramp of $5^{\circ} \mathrm{C} \mathrm{min}^{-1}$ up to $290^{\circ} \mathrm{C}$ followed by a 40 -minute isotherm at $290^{\circ} \mathrm{C}$. Symbols: non-isothermal predictions given by Eq. 7 (circles) and Eq. 8 (triangles). Dashed line: thermal history.

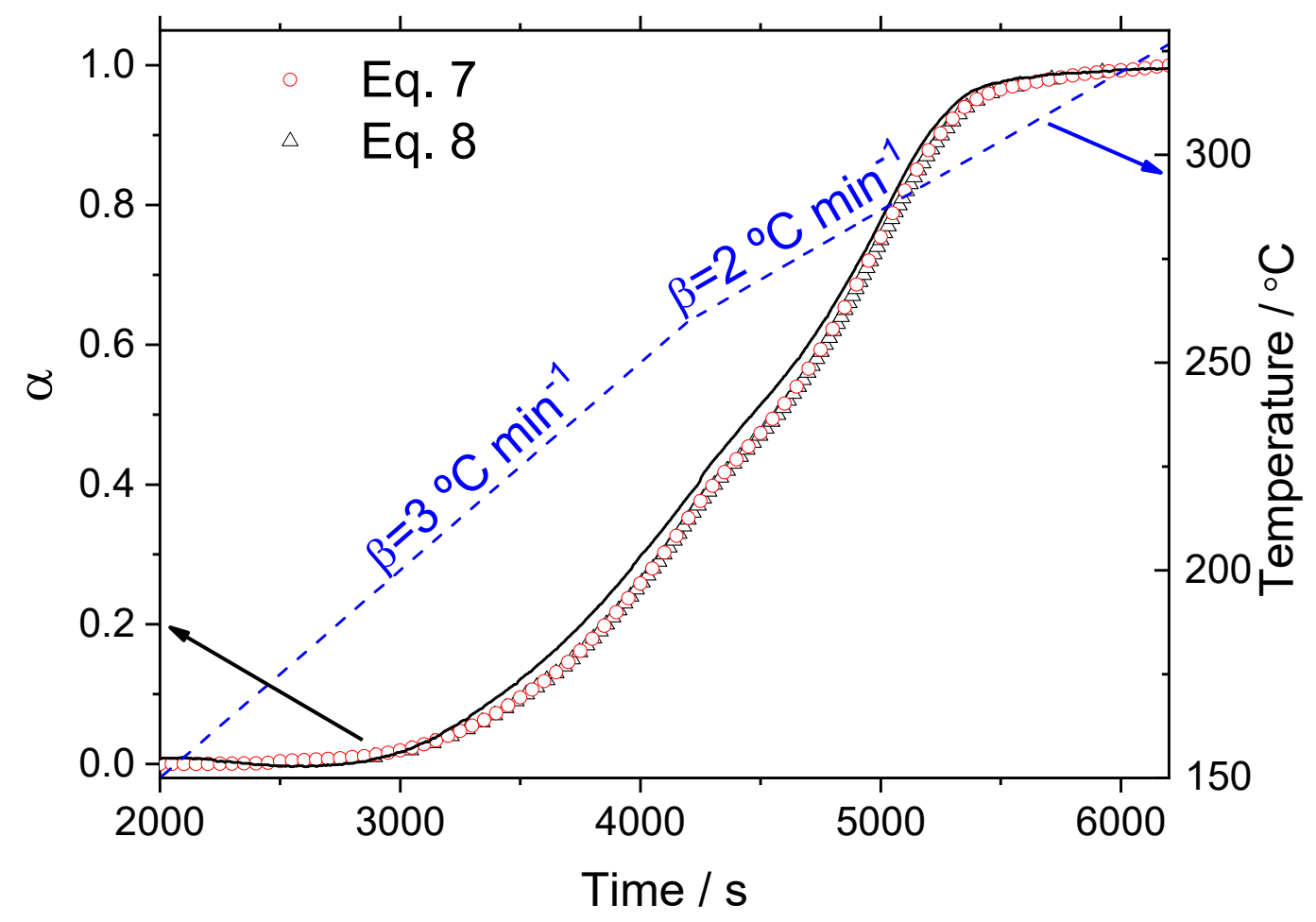


Fig. 7. Solid line: evolution of the transformed fraction when the LF precursor undergoes a thermal treatment consisting of two consecutive heating ramps at 3 and $2{ }^{\circ} \mathrm{C} \mathrm{min}^{-1}$ (dashed line). Symbols: non-isothermal predictions given by Eq. 7 (circles) and Eq. 8 (triangles). Dashed line: thermal history.

\section{Conclusions}

In conclusion, we have shown that the thermal behaviour of films can be analysed with commercial thermal analysis equipment. In particular, a combination of TG analysis and XRD diffraction was successfully used to monitor the evolution and to identify the different processes that take place during pyrolysis and crystal growth of YBCO films.

Additionally, thermal analysis allows us to study the effect of film thickness on the kinetics of the pyrolysis step, which in turn can be used to set the new conditions to completely decompose a film of a given thickness.

In fact, we have also shown that accurate predictions of mass evolution during film pyrolysis can be obtained from kinetic analysis. These predictions can then be used, for instance, to tune the processing conditions in view of reducing the processing time while slowing down the transformation rate at the critical stages, with the aim to prevent crack formation and high film porosity.

To sum up, thermal analysis is a useful tool to monitor the different thermal steps of the CSD methodology in-situ, and to optimize the processes that take place during the growth of oxide films from chemical solution deposition methods.

\section{Acknowledgments}

This work was funded by Ministerio de Ciencia, Innovación y Universidades (grant number RTI2018095853-B-C21); it was also supported by the Generalitat de Catalunya (2017-SGR-1519) and the Universitat de Girona (UdG, contract number MPCUdG2016/059).

\section{Appendix}

In this appendix we describe the iterative method of Eq. 8 to predict the evolution, $\alpha(t)$, when the sample is submitted to an arbitrary temperature program $T(t)$. The method is based on the activation energy, $E_{\alpha}$, obtained from the application of the isoconversional analysis (in this method, the other kinetic parameter, i.e. $A_{\alpha} f(\alpha)$, is not used). It determines the time, $t_{j}$, needed to reach $\alpha_{j}$, where $\alpha_{j}=j / N$ corresponds to the discretization used in the isoconversional analysis, $\Delta \alpha_{j}=\alpha_{j}-\alpha_{j-1}$.

Rearranging Eq. 5 we obtain,

$$
\frac{d \alpha}{A_{\alpha} f(\alpha)}=\exp \left[-\frac{E_{\alpha}}{R T}\right] d t
$$

Since the left-hand side only depends on $\alpha$ : 


$$
\int_{\alpha_{j-1}}^{\alpha_{j}} \frac{d \alpha}{A_{\alpha} f(\alpha)}=g\left(\alpha_{j}\right)-g\left(\alpha_{j-1}\right)=\Delta g\left(\alpha_{j}\right), \quad g(\alpha) \equiv \int \frac{d u}{A_{u} f(u)},
$$

integration of the right-hand side must be independent of the thermal history. It will be calculated for the $n_{\text {exp }}$ constant heating rate experiments used to determine $E_{\alpha}$ and, also, for the particular thermal history whose $\alpha(t)$ evolution we want to predict.

The right-hand side of Eq.A.1 can be integrated for one heating rate, $\beta_{i}$ :

$$
\Delta h\left(\alpha_{j}\right)=\frac{1}{\beta_{i}} \int_{T_{j-1}}^{T_{j}} \exp \left[-\frac{E_{j}}{R T}\right] d T=\frac{E_{j}}{R \beta_{i}}\left[p\left(\frac{E_{j}}{R T_{j, i}}\right)-p\left(\frac{E_{j}}{R T_{j-1, i}}\right)\right], 1 \leq i \leq n_{\text {exp }}
$$

where $T_{j, i}$ is the temperature when a degree of transformation $\alpha_{j}$ is reached at $\beta_{i}$, and the $p(x)$ function is the so called temperature integral [46] and can be calculated from a Pade's series expansion with high accuracy [29],

$$
\begin{aligned}
& p(x) \equiv \int \frac{\exp (-u)}{u^{2}} d u \\
& \quad \approx \frac{\exp (-x)}{x}\left(\frac{x^{5}+40 x^{4}+552 x^{3}+3168 x^{2}+7092 x+4320}{x^{6}+42 x^{5}+630 x^{4}+4200 x^{3}+12600 x^{2}+15120 x+5040}\right)^{(}
\end{aligned}
$$

Note that the $T_{j, i}$ values are precisely the $T_{\alpha, i}$ values used to determine $E_{\alpha}$ (see Fig. 5). To be consistent with the kinetic analysis, in the integration of Eq. A.3 we have assumed that $E_{\alpha}=E_{j}$ is constant over the $\Delta \alpha_{j}$ interval.

The right-hand side of Eq. A.3 can be calculated from any of the different experiments. To minimize errors, instead of taking one particular heating rate, we use the average value of the $n_{\exp }$ performed:

$$
\overline{\Delta h}\left(\alpha_{j}\right)=\frac{1}{n_{\exp }} \sum_{i=1}^{n_{\exp }} \frac{E_{j}}{R \beta_{i}}\left[p\left(\frac{E_{j}}{R T_{j, i}}\right)-p\left(\frac{E_{j}}{R T_{j-1, i}}\right)\right]
$$

Alternatively, the right-hand side of Eq. A.1 can be calculated for the particular temperature program of our prediction, $T(t)$ :

$$
\Delta q\left(\alpha_{j}\right)=\int_{t_{j-1}}^{t_{j}} \exp \left(-\frac{E_{j}}{R T(t)}\right) d t
$$

Since, we are using a discretization of this temperature program, $T_{k}$ and $t_{k}$, where $t_{k+1}=$ $t_{k}+\Delta t$ and $T_{k}=T\left(t_{k}\right)$, the integral of the right-hand side of Eq. A.6 can be calculated as a summation over finite time intervals $\Delta t$. Unfortunately, the discretization of the temperature program, $t_{k}$, may not coincide with the time, $t_{j}$, needed to reach $\alpha_{j}$ (see scheme A.1). Thus, we need to correct the first and the last term of the summation to account for the actual time intervals; we define $t_{k_{j}}$ as the largest value of $t_{k}$ that is smaller than $t_{j}$, i.e., $t_{k_{j}}<t_{j}<t_{k_{j}+1}$ ( $k_{j}$ is the $k$ index of the nearest time bellow $t_{j}$ ). Thus, the summation over finite time intervals of Eq. A.6 becomes, 


$$
\begin{aligned}
\Delta q\left(\alpha_{j}\right)=\exp & \left(-\frac{E_{j}}{R T_{k_{j-1}}}\right)\left(t_{k_{j-1}+1}-t_{j-1}\right)+\sum_{k=k_{j-1}+2}^{k_{j}} \exp \left(-\frac{E_{j}}{R T_{k}}\right) \Delta t \\
& +\exp \left(-\frac{E_{j}}{R T_{k_{j}}}\right)\left(t_{j}-t_{k_{j}}\right) .
\end{aligned}
$$

$t_{k_{j}}$ can be determined performing, step by step, the summation of Eq. A.7:

$$
\exp \left(-\frac{E_{j}}{R T_{k_{j-1}}}\right)\left(t_{k_{j-1}+1}-t_{j-1}\right)+\sum_{k=k_{j-1}+2}^{k_{j}} \exp \left(-\frac{E_{j}}{R T_{k}}\right) \Delta t \leq \overline{\Delta h}\left(\alpha_{j}\right)
$$

$k_{j}$ is the largest $k$ index that keeps the previous summation below $\overline{\Delta h}\left(\alpha_{j}\right)$ (note that the value of $\overline{\Delta h}\left(\alpha_{j}\right)$ can be determined from Eq. A.5 and that $k_{j-1}$ is known from the previous iteration).

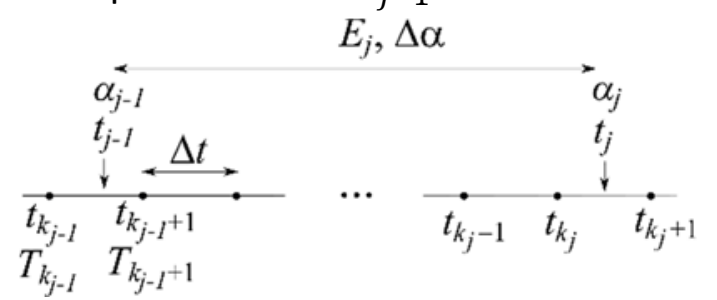

Scheme A.1. Discretization of temperature and degree of transformation, Eq. 8.

Since the right-hand side of Eq. $\mathrm{A} 1$ is independent of the thermal history, then $\overline{\Delta h}=\Delta q$, and $t_{j}$ is obtained equating Eqs. A.5 and A.7:

$$
\begin{aligned}
t_{j}=t_{k_{j}}+\left\{\frac{1}{n_{\exp }} \sum_{i=1}^{n_{\text {exp }}} \frac{E_{j}}{R \beta_{i}}\left[p\left(\frac{E_{j}}{R T_{j, i}}\right)-p\left(\frac{E_{j}}{R T_{j-1, i}}\right)\right]\right. \\
-\left[\exp \left(-\frac{E_{j}}{R T_{k_{j-1}}}\right)\left(t_{k_{j-1}+1}-t_{j-1}\right)\right. \\
\left.\left.+\sum_{k=k_{j-1}+2}^{k_{j}} \exp \left(-\frac{E_{j}}{R T_{k}}\right) \Delta t\right]\right\} \exp \left(-\frac{E_{j}}{R T_{k_{j}}}\right) .
\end{aligned}
$$

Scheme A.2 is a flowchart that summarizes the steps to calculate the predicted evolution.

Finally, $t_{j}$ is obtained from Eqs. A.5 and A.7: 


$$
\begin{aligned}
t_{j}=t_{k_{j}}+\left\{\frac{1}{N_{\exp }} \sum_{i=1}^{N_{\text {exp }}} \frac{E_{j}}{R \beta_{i}}\left[p\left(\frac{E_{j}}{R T_{j, i}}\right)-p\left(\frac{E_{j}}{R T_{j-1, i}}\right)\right]\right. \\
-\left[\exp \left(-\frac{E_{j}}{R T_{k_{j-1}}}\right)\left(t_{k_{j-1}+1}-t_{j-1}\right)\right. \\
\left.\left.+\sum_{k=k_{j-1}+2}^{k_{j}} \exp \left(-\frac{E_{j}}{R T_{k}}\right) \Delta t\right]\right\} \exp \left(-\frac{E_{j}}{R T_{k_{j}}}\right)
\end{aligned}
$$

Scheme A.2 is a flowchart that summarizes the steps to calculate the predicted evolution.

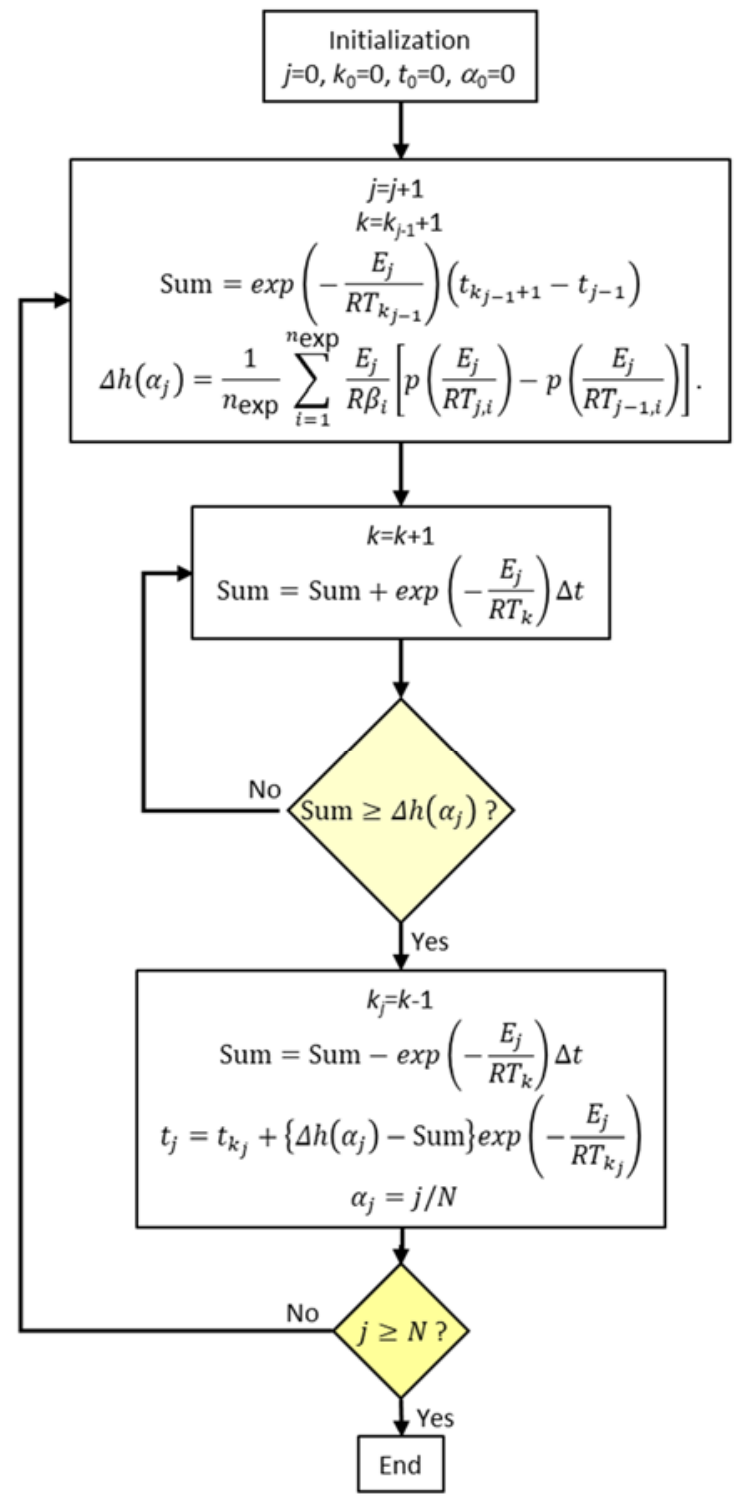

Scheme A.2. Flowchart for the calculation of the predicted evolution, Eq. 8. 


\section{References}

1. Rasi S, Silveri F, Ricart S, Obradors X, Puig T, Roura-Grabulosa P, et al. Thermal decomposition of CuProp 2 : In-situ analysis of film and powder pyrolysis. J Anal Appl Pyrolysis. 2019;140:31220.

2. Rasi S, Ricart S, Obradors $X$, Puig T, Roura P, Farjas J. Thermal decomposition of yttrium propionate: film and powder. J Anal Appl Pyrolysis. 2018;133:225-33.

3. Rasi S, Ricart S, Obradors X, Puig T, Roura-Grabulosa P, Farjas J. Radical and oxydative pathways in the pyrolysis of a barium propionate-acetate salt. J Anal Appl Pyrolysis. 2019;141:104640.

4. Eloussifi H, Farjas J, Roura P, Ricart S, Puig T, Obradors X, et al. Thermoanalytical study of the decomposition of yttrium trifluoroacetate thin films. Thin Solid Films. 2013;545:200-4.

5. Eloussifi H, Farjas J, Roura P, Ricart S, Puig T, Obradors X, et al. Thermal decomposition of barium trifluoroacetate thin films. Thermochim Acta. 2013;556:58-62.

6. Sanchez-Rodriguez D, Farjas J, Roura P, Ricart S, Mestres N, Obradors X, et al. Thermal Analysis for Low Temperature Synthesis of Oxide Thin Films from Chemical Solutions. J Phys Chem C. 2013;117:20133-8.

7. Roura P, Farjas J, Camps J, Ricart S, Arbiol J, Puig T, et al. Decomposition processes and structural transformations of cerium propionate into nanocrystalline ceria at different oxygen partial pressures. J Nanoparticle Res. 2011;13:4085-96.

8. Roura P, Farjas J, Ricart S, Aklalouch M, Guzman R, Arbiol J, et al. Synthesis of nanocrystalline ceria thin films by low-temperature thermal decomposition of Ce-propionate. Thin Solid Films. 2012;520:1949-53.

9. Farjas J, Sanchez-Rodriguez D, Eloussifi H, Hidalgo RC, Roura P, Ricart S, et al. Can We Trust on the Thermal Analysis of Metal Organic Powders for thin film preparation? Jain M, Obradors X, Jia Q, Schwartz RW, editors. MRS Proc. 2012;1449:13-8.

10. Sánchez-Rodriguez D, Farjas J, Roura P. The critical conditions for thermal explosion in a system heated at a constant rate. Combust Flame. 2017;186:211-9.

11. Sánchez-Rodriguez D, Farjas J, Roura P. The critical condition for thermal explosion in an isoperibolic system. AIChE J. 2017;63:3979-93.

12. Schneller T, Waser R, Kosec M, Payne D, editors. Chemical Solution Deposition of Functional Oxide Thin Films. Springer Vienna; 2013.

13. Obradors X, Puig T, Gibert M, Queraltó A, Zabaleta J, Mestres N. Chemical solution route to selfassembled epitaxial oxide nanostructures. Chem Soc Rev. 2014;43:2200-25.

14. Larbalestier D, Gurevich A, Feldmann DM, Polyanskii A. High-Tc superconducting materials for electric power applications. Nature. 2001;414:368-77.

15. Obradors X, Puig T. Coated conductors for power applications: materials challenges. Supercond Sci Technol. 2014;27:044003.

16. Marchionini BG, Yamada Y, Martini L, Ohsaki H. High-Temperature Superconductivity: A Roadmap for Electric Power Sector Applications, 2015-2030. IEEE Trans Appl Supercond. 2017;27:1-7.

17. Oh SS, Kim HS, Ha HS, Ko RK, Ha DW, Lee H, et al. Progress in research and development for REBCO coated conductors by reactive co-evaporation. Prog Supercond Cryog. 2013;15:1-5. 
18. Stadel O, Schmidt J, Wahl G, Weiss F, Selbmann D, Eickemeyer J, et al. Continuous YBCO deposition by MOCVD for coated conductors. Phys C Supercond. 2002;372-376:751-4.

19. Vermeir P, Cardinael I, Schaubroeck J, Verbeken K, Michael B, Lommens $P$, et al. Elucidation of the Mechanism in Fluorine-Free Prepared $\mathrm{YBa}_{2} \mathrm{Cu}_{3} \mathrm{O}_{7-\delta}$ Coatings. Inorg Chem. 2010;49:4471-7.

20. Gupta A., Jagannathan R, Cooper El, Giess E a., Landman JI, Hussey BW. Superconducting oxide films with high transition temperature prepared from metal trifluoroacetate precursors. Appl Phys Lett. 1988;52:2077.

21. Solovyov V, Dimitrov IK, Li Q. Growth of thick YBa2Cu3O7 layers via a barium fluoride process. Supercond Sci Technol. 2013;26:13001-20.

22. Obradors X, Puig T, Ricart S, Coll M, Gazquez J, Palau A, et al. Growth, nanostructure and vortex pinning in superconducting $\mathrm{YBa}_{2} \mathrm{Cu}_{3} \mathrm{O}_{7}$ thin films based on trifluoroacetate solutions. Supercond Sci Technol. 2012;25:123001.

23. Puig T, González JC, Pomar A, Mestres N, Castaño O, Coll M, et al. The influence of growth conditions on the microstructure and critical currents of TFA-MOD $\mathrm{YBa}_{2} \mathrm{Cu}_{3} \mathrm{O}_{7}$ films. Supercond Sci Technol. 2005;18:1141-50.

24. Yoshizumi M, Seleznev I, Cima MJ. Reactions of oxyfluoride precursors for the preparation of barium yttrium cuprate films. Phys C Supercond. 2004;403:191-9.

25. Araki T, Hirabayashi I. Review of a chemical approach to $\mathrm{YBa}_{2} \mathrm{Cu}_{3} \mathrm{O}_{7-\mathrm{x}}$-coated superconductors - metalorganic deposition using trifluoroacetates. Supercond Sci Technol. 2003;16:71-94.

26. Chen $Y$, Wu C, Zhao G, You C. An advanced low-fluorine solution route for fabrication of highperformance YBCO superconducting films. Supercond Sci Technol. 2012;25:069501.

27. Palmer X, Pop C, Eloussi H, Villarejo B, Roura P, Farjas J, et al. Solution design for low- fluorine trifluoroacetate route to $\mathrm{YBa}_{2} \mathrm{Cu}_{3} \mathrm{O}_{7}$ films. Supercond Sci Technol. 2016;29:024002.

28. Pop C, Villarejo B, Pino F, Mundet B, Ricart S, de Palau M, et al. Growth of all-chemical high critical current $\mathrm{YBa}_{2} \mathrm{Cu}_{3} \mathrm{O}_{7-\delta}$ thick films and coated conductors. Supercond Sci Technol. 2019;32:015004.

29. Farjas J, Roura P. Isoconversional analysis of solid state transformations. A critical review. Part I. Single step transformations with constant activation energy. J Therm Anal Calorim. 2011;105:757-66.

30. Farjas J, Roura P. Isoconversional analysis of solid state transformations. A critical review. Part II. Complex transformations. J Therm Anal Calorim. 2011;105:767-73.

31. Brown ME, Maciejewski M, Vyazovkin S, Nomen R, Sempere J, Burnham A, et al. Computational aspects of kinetic analysis: Part A: The ICTAC kinetics project-data, methods and results. Thermochim Acta. 2000;355:125-43.

32. Vyazovkin S, Burnham AK, Criado JM, Pérez-maqueda LA, Popescu C, Sbirrazzuoli N. ICTAC Kinetics Committee recommendations for performing kinetic computations on thermal analysis data. Thermochim Acta. 2011;520:1-19.

33. Calleja A, Ricart S, Palmer X, Luccas RF, Puig T, Obradors X. Water determination of precursor solutions with oxidant cations by the Karl Fischer method: the YBCO-TFA case. J Sol-Gel Sci Technol. 2010;53:347-52. 
34. Gàzquez J, Sandiumenge F, Coll M, Pomar A, Mestres N, Puig T, et al. Precursor Evolution and Nucleation Mechanism of $\mathrm{YBa}_{2} \mathrm{Cu}_{3} \mathrm{O}_{x}$ Films by TFA Metal-Organic Decomposition. Chem Mater. 2006;18:6211-9.

35. Li Z, Coll M, Mundet B, Palau A, Puig T, Obradors X. Accelerated growth by flash heating of high critical current trifluoroacetate solution derived epitaxial superconducting $\mathrm{YBa}_{2} \mathrm{Cu}_{3} \mathrm{O}_{7}$ films. J Mater Chem C. 2019;7:4748-59.

36. Sánchez-Valdés $C F$, Puig $T$, Obradors $X$. In situ study through electrical resistance of growth rate of trifluoroacetate-based solution-derived $\mathrm{YBa}_{2} \mathrm{Cu}_{3} \mathrm{O}_{7}$ films. Supercond Sci Technol. 2015;28:024006.

37. Roura P, Farjas J, Eloussifi H, Carreras L, Ricart S, Puig T, et al. Thermal analysis of metal organic precursors for functional oxide preparation: Thin films versus powders. Thermochim Acta. 2015;601:1-8.

38. Zalamova K, Romà N, Pomar A, Morlens S, Puig T, Gázquez J, et al. Smooth Stress Relief of Trifluoroacetate Metal-Organic Solutions for $\mathrm{YBa}_{2} \mathrm{Cu}_{3} \mathrm{O}_{7}$ Film Growth. Chem Mater. 2006;18:5897-906.

39. Holesinger TG, Civale L, Maiorov B, Feldmann DM, Coulter JY, Miller DJ, et al. Progress in Nanoengineered Microstructures for Tunable High-Current, High-Temperature Superconducting Wires. Adv Mater. 2008;20:391-407.

40. Llordés A, Zalamova K, Ricart S, Palau A, Pomar A, Puig T, et al. Evolution of MetalTrifluoroacetate Precursors in the Thermal Decomposition toward High-Performance $\mathrm{YBa}_{2} \mathrm{Cu}_{3} \mathrm{O}_{7}$ Superconducting Films. Chem Mater. 2010;22:1686-94.

41. Vyazovkin S, Wight CA. Kinetics in solids. Annu Rev Phys Chem. 1997;48:125-49.

42. Friedman HL. Kinetics of thermal degradation of char-forming plastics from thermogravimetry. Application to a phenolic plastic. J Polym Sci Part C. 1964;6:183-95.

43. Press WH, Flannery BP, Teukolsky SA, Vetterling WT. Numerical recipes in C: the art of scientific computing. Cambridge: Cambridge University Press; 1994.

44. Farjas J, Roura P. Isoconversional analysis of solid-state transformations. A critical review. Part III. Isothermal and non isothermal predictions. J Therm Anal Calorim. 2012;109:183-91.

45. Eloussifi H, Farjas J, Roura P, Dammak M. Non-isothermal model-free predictions. J Therm Anal Calorim. 2012;108:597-603.

46. Coats AW, Redfern JP. Kinetic Parameters from Thermogravimetric Data. Nature. 1964;201:689. 


\section{Figure captions}

Fig.1: (a) TG analysis of a film obtained from deposition of the TFA solution. Conditions: flowing humid $\mathrm{N}_{2}$, heated at $5^{\circ} \mathrm{C} \mathrm{min}^{-1}$ up to $350^{\circ} \mathrm{C}$, and at $25^{\circ} \mathrm{C} \mathrm{min}^{-1}$ from $350^{\circ} \mathrm{C}$ to $850^{\circ} \mathrm{C}$. Dashed horizontal lines indicate the theoretical final mass to yield the intermediates before YBCO formation. Inset: enlargement of the TG curve in the temperature range from $350^{\circ} \mathrm{C}$ to $850^{\circ} \mathrm{C}$. (b) $X R D$ of the solid residue after decomposition of the TFA-films during pyrolysis and growth at $5^{\circ} \mathrm{C} \mathrm{min}^{-1}$ up to a given temperature (indicated) under a humid $\mathrm{N}_{2}$ flow.

Fig. 2: TG curves of TFA precursor when heated at $5^{\circ} \mathrm{C} \min ^{-1}$ up to $310^{\circ} \mathrm{C}$ and afterwards kept at this temperature for 30 minutes under a flow of humid $\mathrm{N}_{2}$. Increasing the thickness, the decomposition temperature increases. The mass is normalized to the sample mass after solvent evaporation.

Fig. 3. Evolution of the mass (normalized to the mass after solvent evaporation at $200^{\circ} \mathrm{C}$ ) when the $L F$ precursor is heated at several constant rates. Experiments were performed under a flow of humid oxygen. Inset: activation energy determined with the Friedman isoconversional method, Fig. 5.

Fig. 4. Degree of transformation as a function of temperature for four LF films with similar thickness. The solid line is the evolution of the transformed fraction extracted from Fig. 3 . The symbols are the non-isothermal predictions given by Eq. 7 (circles) and Eq. 8 (triangles).

Fig 5. Friedman plot for selected values of the transformed fraction, $\alpha$. Four points are plotted for each $\alpha$ which correspond to $\beta=5,10,20$ and $40^{\circ} \mathrm{C} \mathrm{min}^{-1}$.

Fig. 6. Solid line: evolution of the transformed fraction when the LF precursor film undergoes a treatment with a heating ramp of $5^{\circ} \mathrm{C} \mathrm{min}^{-1}$ up to $290^{\circ} \mathrm{C}$ followed by a 40 -minute isotherm at $290^{\circ} \mathrm{C}$. Symbols: non-isothermal predictions given by Eq. 7 (circles) and Eq. 8 (triangles). Dashed line: thermal history.

Fig. 7. Solid line: evolution of the transformed fraction when the LF precursor undergoes a thermal treatment consisting of two consecutive heating ramps at 3 and $2^{\circ} \mathrm{C} \mathrm{min}{ }^{-1}$ (dashed line). Symbols: non-isothermal predictions given by Eq. 7 (circles) and Eq. 8 (triangles). Dashed line: thermal history.

Scheme A.1. Discretization of temperature and degree of transformation, Eq. 8.

Scheme A.2. Flowchart for the calculation of the predicted evolution, Eq. 8. 